\title{
Conversações fluidas na cibercultura ${ }^{1}$
}

\section{Fluid conversations in cyberculture}

\author{
Alex Teixeira Primo \\ Professor do Programa de Pós-Graduação em Comunicação e Informação da Universidade Federal do Rio Grande do Sul \\ (UFRGS), bolsista de produtividade do CNPq \\ <alex.primo@gmail.com>
}

\section{Vanessa Valiati}

Doutoranda no PPGCOM/UFRGS, professora da Feevale <vanessa.valiati@gmail.com>

\section{Ludmila Lupinacci}

PPGCOM/UFRGS

$<$ ludmila.lupinacci@gmail.com>

\section{Laura Barros}

PPGCOM/UFRGS

$<$ laurabarros5@gmail.com>

\section{RESUMO}

Este artigo visa estudar como o amplo leque de serviços de comunicação on-line participa da criação e manutenção de relações interpessoais na contemporaneidade. $\mathrm{O}$ trabalho investiga como $\mathrm{O}$ entrelaçamento entre os usos de diferentes plataformas digitais vem transformando as práticas de sociabilidade e as conversações no contexto da cibercultura, a partir da articulação de perspectivas teóricas e empíricas sobre tais temas. Atenção especial é conferida a como as pessoas se apropriam desses serviços, combinandoos para atingir variados fins relacionais com públicos diversos e em tempos e lugares distintos. A partir de uma pesquisa empírica com 810 pessoas - residentes nas regiões Sul e Sudeste, maiores de 16 anos e com pelo menos o Ensino Superior Incompleto -, este artigo define e discute o fenômeno que chama de "conversações fluidas".

\section{ABSTRACT}

This article aims to study how the wide range of on-line communication services participates in the creation and maintenance of interpersonal relationships in the contemporary world. We investigate how the interrelation of the uses of different digital plataforms has been transforming sociability and conversational processes in the context of cyberculture, based on the articulation between theoretical and empirical perspectives on those subjects. Special attention is given to how people appropriate these services, combining them to achieve different relational purposes with diverse audiences in various time and places. Based on an empirical survey of 810 people - residents in the South and Southeast regions, over 16 years old and with at least incomplete higher education - , this article defines and discusses the phenomenon that it calls "fluid conversations".

Keywords: Cyberculture. Conversation. Friendship.

1 Pesquisa financiada pelo CNPq. 


\section{Introdução}

O transtorno gerado nas cerca de 20 horas de proibição do WhatsApp no Brasil em 2015 (G1, 2015) evidenciou a dependência dos brasileiros em relação ao serviço, e a representatividade deste na vida de milhões de pessoas. Este artigo visa justamente estudar como diferentes serviços de comunicação on-line ${ }^{1}$ participam da criação e manutenção de relações interpessoais na contemporaneidade.

Apesar da pertinência do tema, um panorama mais completo dos usos dos diferentes serviços de comunicação digital - e das motivações por trás da adoção de determinados sistemas para formas específicas de conversação on-line ${ }^{2}$ - ainda se faz necessário. Embora órgãos nacionais como o IBGE e o IBOPE dediquem-se a mapear o consumo de mídia, incluindo meios digitais, são organizações norte-americanas como o Pew Research Center e a comScore que vêm desenvolvendo com maior constância estudos sobre serviços de comunicação on-line.

Porém, mesmo em pesquisas estrangeiras observa-se um enfoque quase sempre demográfico. Já a nossa proposta não é a de fazer um mapeamento de representatividade populacional nos diferentes serviços de comunicação on-line, mas sim discutir o entrelaçamento dos usos dessas plataformas com as transformações nas práticas da conversação, na criação e manutenção de amizades, a partir da articulação de perspectivas teóricas e empíricas sobre tais temas.

Além disso, este trabalho não está, diferentemente de tantos outros - como Lenhart (2015), Lenhart e outros (2015), Madden e outros (2013) - , focado nas práticas interacionais dos adolescentes. É possível notar que estudos que investigam os processos de criação e manutenção de amizades no ambiente on-line, bem como de relações românticas ou sexuais, normalmente se dedicam às práticas dos teens. Neste trabalho, damos prioridade e visibilidade aos usos de indivíduos adultos e com maior grau de escolaridade.

Este artigo surge como primeiro desdobramento de uma pesquisa maior desenvolvida no Laboratório de Interação Mediada por Computador (Limc, UFRGS) sobre amizade e conversações através de serviços on-line. Aqui

1 Por serviços de comunicação on-line entendemos todo protocolo e interface, tanto aplicativos (como ICQ e WhatsApp) quanto sites (fórums e sites de redes sociais), utilizados em aparatos conectados à internet (como desktops, notebooks smartphones, tablets, smart TVs), utilizados para a interação interpessoal. Vale lembrar que uma conversa interpessoal não é o mesmo que presencial, já que o encontro interpessoal pode ocorrer à distância, através dos serviços on-line mencionados.

2 Para uma revisão sobre conversações on-line e o método de análise de conversações, ver Recuero (2012) e Primo e Smaniotto (2006). 
apresentamos os primeiros resultados da fase quantitativa da pesquisa e discutimos diferentes formas de interação interpessoais on-line praticadas por brasileiros, residentes nas regiões Sul e Sudeste, maiores de 16 anos e com pelo menos o ensino superior incompleto.

Longe de ser uma análise tecnicista, é importante salientar que o foco desta pesquisa não é a mera interação homem-máquina - o uso que se dá para as tecnologias digitais - , mas sim como ocorre a interação interpessoal com a mediação das tecnologias digitais. Vale ressaltar que por mediação não entendemos a simples transmissão, mas sim a ação e participação de agentes digitais na conversação humana, e como a intervenção deles transforma essa forma de associação (Latour, 2005).

\section{Amizade na cibercultura}

Diante da proliferação dos sites de redes sociais e do crescente número de "amigos", seguidores e contatos em tais serviços on-line, poder-se-ia supor que a amizade vive seu grande pico na história da humanidade. Por outro lado, a convivência com amigos é desafiada pela rápida e estressante vida contemporânea. Como as práticas amistosas estão intimamente vinculadas à cultura de cada época e lugar, esta seção visa discutir como tais processos estão sendo atualizados em tempos de cibercultura.

Putnam (2000), que popularizou o conceito de capital social, diagnostica um declínio na convivência social desde os anos 1950, na direção de um maior individualismo. A família passa a conviver menos no lar, a amizade e as relações amorosas se transmutam na vida atribulada das cidades. No trabalho os relacionamentos tem dificuldade de se fortalecer, em virtude principalmente do sistema de terceirização e serviços de curto prazo.

Como se sabe, as tecnologias digitais facilitam a manutenção de amizades, apesar de distâncias geográficas e temporais, e a criação de novos laços. Por outro lado, Gergen (2000) aponta que os relacionamentos passam a ter dificuldades de se estabilizar diante dos modos saturados da vida na pós-modernidade. O self dá lugar à persona, a imagem persuasiva que se quer mostrar aos outros. Estar em relação (relatedness) passa a ser mais importante que o relacionamento (relationship) em si.

A respeito dos relacionamentos no mundo líquido ${ }^{3}$ contemporâneo, e surpreso pela busca artificial por um grande número de "amigos" em sites de redes sociais, Bauman (2004) afirma que hoje as parcerias estão frouxas e

3 Para Bauman (2001), a "fluidez" ou "liquidez" podem ser consideradas metáforas adequadas a uma nova fase da modernidade. Para o autor, os líquidos, enquanto variedade dos fluidos, não se limitam a formas determinadas e estão sempre sujeitos a mudá-las: se movem facilmente, contornam obstáculos 
revogáveis. Na era das "amizades Facebook" (Bauman, 2013), há uma facilidade muito grande em se conectar e desconectar. No vocabulário cotidiano, "conexões" e "conectar-se" substituem "relacionamentos" e "relacionar-se". Em tempo, vale reconhecer que a adoção de terminologia informática (conexão e desconexão) no domínio dos relacionamentos amistosos é reveladora de como a tecnologia intervém significativamente nos processos relacionais.

É também significativo observar a proposta de Boyd e Elisson (2007) de uma distinção entre amizade on-line e off-line. Ao estudar os sites de redes sociais, as autoras sugerem a grafia Friend, com maiúscula, para referir-se à lista articulada de pessoas com quem se interage nos sites de redes sociais, e friend (com minúscula) para o que chamam de "uso coloquial" do termo. Esta divisão artificial, que separa relacionamentos on-line daqueles off-line, acaba por reduzir a prática da amizade no Facebook, por exemplo, a uma lista de conexões.

Ao final desta argumentação, contudo, não se pode concluir que a amizade seguiu uma percurso linear, que parte de relacionamentos honestos e sinceros, conforme descrito pelos filósofo gregos, e descamba tragicamente em um conjunto de contatos frios e utilitários. É com este alerta necessário que neste artigo apresentamos os primeiros resultados de uma pesquisa maior sobre amizade e conversações através de serviços de comunicação on-line. Nos interessa discutir as conversações mantidas e prolongadas durante o dia (ou dias) através de tecnologias que nos facultam permanecer continuamente disponíveis. Queremos observar o que há de prazeroso, lúdico e divertido nos relacionamentos on-line. Da mesma forma, queremos refletir sobre como tal conexão permanente também pode ser estressante, opressiva, causar ansiedade, mal-entendidos. Como amizades podem ser fortalecidas, novos relacionamentos serem iniciados e como rompimentos podem ocorrer on-line. Tais reflexões, contudo, não focarão simplesmente a tecnologia, como se ela determinasse a vida implacavelmente. Para tanto, as investigações empíricas que estamos conduzindo buscam manter sempre à vista os modos de ser, saber e fazer de nosso tempo.

\section{Conversações fluidas}

Ao estudar as conversações mantidas em uma comunidade de blogs, Primo e Smaniotto (2006) verificaram que os blogueiros participantes do coletivo Insanus escreviam posts respondendo a postagens escritas em blogs de outros colegas do grupo. Além disso, Primo e Smaniotto observaram a intrincada

e não são facilmente contidos; são associados à ideia de leveza, pois "fluem", "escorrem", "transbordam" $(2001$, p.8). 
estrutura dos comentários nos posts, já que múltiplas conversações eram estabelecidas no mesmo espaço. Ou seja, mesmo que os comentários fossem apresentados na interface de forma linear e cronológica, cada texto poderia referir-se a comentários anteriores que não estavam imediatamente acima dele. Um leitor desatento poderia ter dificuldade de seguir as diversas conversações em andamento ou poderia até mesmo nem reconhecer a existência delas.

Durante a pesquisa das conversações entre os blogueiros da comunidade Insanus (cuja maioria já mantinha forte amizade antes da emergência da blogosfera), Primo e Smaniotto (2006) observaram que eles interagiam não apenas através dos blogs, mas também através de outros serviços populares na época (SMS, MSN, lista de discussão, etc.). Os autores então concluíram que as conversações poderiam ser intra-blogs (nos comentários de um blog), interblogs (posts e comentários em um blog citando textos de outro blog) e extrablogs (fazendo uso de outros serviços de comunicação). A partir desse estudo, Primo e Smaniotto (2006) apontaram a necessidade de estudos quantitativos e qualitativos para o estudo do que chamaram de "fluidos conversacionais", "que 'escorrem' por entre diferentes espaços, meios, redes (Internet, telefonia celular, por exemplo) e momentos" (Primo e Smaniotto, 2006, p. 268). A presente pesquisa segue tal caminho apontado, buscando resultados empíricos que fomentem uma melhor compreensão do fenômeno.

A pesquisa que estamos desenvolvendo quer compreender em que condições ocorrem o que chamamos de "conversações fluidas". Esta seção visa recuperar outros estudos focados na inter-relação entre várias tecnologias digitais para a manutenção de amizades na internet e para a condução de conversações mediadas digitalmente.

Vale lembrar que tecnologias digitais já foram tratadas como formas limitadas para comunicação e relacionamentos em virtude da menor disponibilidade de pistas não-verbais, em comparação com os encontros facea-face (Haythornthwaite, 2005; Chambers, 2013). O que se percebe hoje é um uso constante de serviços on-line para a interação continuada entre amigos, familiares, colegas de trabalho, etc.

Com a popularização das plataformas de interação on-line e a miniaturização dos artefatos digitais, as pessoas hoje estão em constante estado de conversação. Esse estado de alerta traduz uma característica do ambiente always on (Turkle, 2006; Pellanda, 2008), no qual o indivíduo está conectado a vários espaços simultaneamente. Segundo Pellanda (2008, p. 4-5), "não estar conectado pode significar estar excluído, fora do círculo de conversa, de um modo ou estilo de vida". E, conforme destaca Chambers (2013), tais relações 
à distância já não dependem de um certo tipo de tecnologia, mas de uma pluralidade de meios.

Ao estudar a interação mediada entre pesquisadores de um mesmo centro de pesquisa e aquela mantida entre participantes de um curso a distância, Haythornthwaite (2005) observou um processo comunicacional que chamou de "multiplexidade midiática" (media multiplexity ${ }^{4}$ ). Questionando-se sobre quem falava com quem e através de quais meios, a autora concluiu que quanto mais forte era o laço entre as pessoas, maior era o número de mídias utilizadas para interagirem. Além disso, percebeu que amigos e colegas próximos buscavam ativa e conjuntamente meios que pudessem compensar as deficiências ou indisponibilidade de outros canais.

$\mathrm{Na}$ comunicação interpessoal não-presencial, as pessoas escolhem os meios para conversarem a partir dos recursos expressivos e estéticos que cada um oferece. Para esta circunstância, a importância do conceito de affordances (Gibson, 1977) vem sendo cada vez mais reconhecida. Além das potencialidades oferecidas pelo dispositivo (aquilo que pode ser realizado), a teoria das affordances também destaca aquilo que ele limita. Por exemplo, enquanto o e-mail era uma das formas mais usadas para a interação na internet, muitos mal-entendidos ocorriam em virtude da falta de pistas não verbais. Com o desenvolvimento de outros serviços on-line, conforme mostram Madianou e Miller (2013), o e-mail passa ser usado em conjunto ou alternadamente com uma série de outros meios que oferecem diferentes recursos.

A partir de observações etnográficas sobre como famílias das Filipinas e de Trinidad mantinham contato com seus parentes em outros países, e buscando ultrapassar o entendimento simplista de uma mera combinação tecnológica, Madianou e Miller (2013) propõem o conceito de polimídia (polymedia). Ao recusar o foco nas qualidades discretas de cada meio, os autores defendem que polimídia refere-se a um ambiente de affordances - no qual cada meio é observado em relação a todos os outros - e a uma estrutura de oportunidades (a escolha de certos meios para certos fins). Como custo e acesso aos dispositivos digitais deixou de ser uma barreira significativa, a escolha de cada meio para cada finalidade relacional torna-se bastante reveladora. Logo, a riqueza do

4 Em análise de redes sociais o termo "multiplex" refere-se a laços constituídos por muitas formas de relações. Por exemplo, um laço pode ter apenas uma relação: ser colega de trabalho. Por outro lado, se essas pessoas também compartilham informações entre si, ajudam-se financeiramente, frequentam eventos juntas, o laço que as une seria composto por muitas relações. Conforme Garton, Haythornthwaite e Wellman (1997), esse seria um laço multiplex. Os autores afirmam que tal laço é normalmente mais íntimo, voluntário e durável. 
conceito de polimídia se encontra na percepção de como esse ambiente e as escolhas midiáticas que as pessoas fazem repercutem em seus relacionamentos e suas emoções.

Madianou e Miller (2013) também concluem que as pessoas reconhecem que certos meios se mostram mais adequados para certos atos sociais. E mais, muitos relacionamentos acabam criando uma configuração midiática particular para suas formas relacionais típicas. Tal processo pode ser verificado no estudo de Boyd e Marwick (2011) sobre privacidade em interações na internet. As autoras observam que os adolescentes usam múltiplos canais de comunicação para diferentes fins. Por exemplo, usar o Facebook para postagens públicas e o Twitter para interações mais íntimas. Contudo, as autoras notam que tais escolhas não se devem apenas às affordances dos serviços, mas também em vista das práticas relacionais construídas em torno deles. Boyd e Marwick também encontraram um comportamento compartilhado tanto por adolescentes quanto por adultos: separar contextos (conversa com familiares, conversas íntimas com amigos) em serviços diferentes (Facebook, MySpace e Twitter).

Como o passar dos anos, os sites de redes sociais vêm continuamente ganhando importância no cotidiano comunicacional das pessoas por reunir em uma mesma plataforma funcionalidades antes disponíveis em serviços digitais diferentes. Elisson e Boyd (2013) comentam que tais sites combinam variados recursos expressivos (textuais, multimídia) e múltiplos modos de comunicação: um-um e um-todos, síncrono e assíncrono, público e privado.

A rigor, a multimodalidade é um tema estudado por linguistas há décadas e refere-se ao uso de diversos recursos em eventos comunicacionais (Leeuwen, 2012). As conversações na internet, conforme aponta Recuero (2012), são tipicamente multimodais.

A multimodalidade, portanto, acarreta a migração da conversação entre várias ferramentas, o que indica que é difícil seguir essa conversação. A característica da migração, assim, refere-se à capacidade das conversações de se espalharem entre várias ferramentas, sofrendo alterações na sua estrutura e organização, mas permanecendo como um único evento de fala. Ela também está relacionada com as características das ferramentas, suas apropriações e limitações. (Recuero, 2012, p. 63).

Além da multimodalidade, é importante destacar que em sites de redes sociais é possível comunicar-se com pessoas de diferentes ambientes e com os quais se mantém laços de intensidades variadas (familiares, colegas de trabalho, amigos, etc.). Enquanto isso pode facilitar a manutenção do contato com pessoas e grupos diferentes, com alguma frequência ocorre o que Marwick e Boyd (2011) 
chamam de "colapso de contextos". Ou seja, situações constrangedoras podem acontecer à medida que mensagens que deveriam ser lidas por apenas um grupo são também exibidas para outras pessoas, aquém da audiência pretendida. Por outro lado, a exposição a posts e comentários de amigos de amigos permite que redes diferentes entrem em contato, viabilizando a circulação de outras perspectivas.

A popularização dos sites de redes sociais poderia levantar a suspeita de que o uso integrado de diferentes serviços digitais de comunicação online seria desnecessária. Ora, apenas o Facebook seria suficiente para as mais diferentes necessidades, tendo em vista o leque multimodal que oferece. Contudo, a supremacia isolada do Facebook não parece que se confirmará. Em 2014 a mídia relatou com grande interesse a saída de muitos adolescentes do Facebook, fugindo da vigilância dos seus pais e familiares que passaram a usar a plataforma (Jivanda, 2013; Tate, 2013). Mesmo assim, o incremento no uso de Instagram e WhatsApp, para finalidades diferentes, não diminuiu o controle da empresa Facebook, já que aqueles dois serviços são suas propriedades. Por outro lado, o crescimento de aplicativos como Snapchat, serviços de redes sociais para fins específicos (como buscar parceiros sexuais) e determinados grupos (público gay), pode-se antever como a prática polimidiática e as conversações fluidas não tendem a desaparecer.

A partir dos subsídios teóricos elencados até aqui, é possível agora oferecer uma proposta conceitual sobre a fluidez das conversações, ampliando o primeiro tratamento de Primo e Smaniotto (2006). Por conversações fluidas entendemos as interações dialogais que ocorrem em ambientes polimidiáticos, trocadas em mais de um serviço de comunicação digital, possivelmente usando variados aparatos técnicos (desktop, smartphone, Smart TV) e redes de conexão (cabo, 4G). Tais conversas síncronas e/ou assíncronas constituem uma intrincada estrutura hipertextual e multimodal, que interconecta agentes humanos e não humanos, tempos e lugares.

Apesar de nossa definição enfatizar os serviços on-line, é preciso alertar que conversações fluidas podem também interligar meios de comunicação não ligados à internet (como telefonia tradicional, um bilhete, etc.) e encontros presenciais. Selfies em um bar, publicados no Snapchat e que motivam diálogos no WhatsApp e no próprio estabelecimento comercial (uma amiga mostra a resposta para outra em seu celular) são hoje situações comuns, que mostram como lugares, tempos e tecnologias são atraídos em uma situação conversacional marcada por grande hibridismo. 
A partir dos resultados da pesquisa empírica que apresentaremos nas próximas seções, a definição de conversações fluidas será ampliada e complexificada.

\section{Metodologia}

Para a coleta de dados empíricos sobre práticas de conversação na internet, disponibilizamos um questionário on-line criado na plataforma Google Forms - composto por 44 questões, sendo 8 delas de múltipla escolha, 19 de escala gradativa, 15 em que o respondente selecionava múltiplas opções a partir de uma lista e 2 perguntas abertas - , em que são abordadas algumas das principais ações e intenções para o uso de serviços de interação na internet. 0 questionário ficou disponível para preenchimento entre os dias 27 de outubro e 24 de novembro de 2015. Sua divulgação foi feita em diferentes plataformas, através do compartilhamento de cards que convidavam as pessoas a responder à pesquisa e compartilhá-la em suas redes, além de post patrocinado no Facebook.

Originalmente, foram obtidas 1050 respostas, de respondentes residentes em 25 diferentes estados - sendo 55,7\% destes indivíduos da região Sul, e 25,6\% do Sudeste, havendo portanto uma evidente discrepância de representatividade entre estas regiões do país e as demais, que somadas concentraram apenas $18,7 \%$ das respostas. Além disso, dentre esse total de respondentes, $96 \%$ afirmou possuir, no mínimo, Ensino Superior incompleto. Diante da baixa relevância estatística das respostas das regiões pouco representadas e de pessoas mais jovens, optou-se por considerar apenas as 810 respostas de pessoas maiores de 16 anos, residentes nas regiões Sul e Sudeste, e com pelo menos Ensino Superior Incompleto. Os dados demográficos podem ser observados na Figura 1: 


\section{- Figura 1 - Dados demográficos}

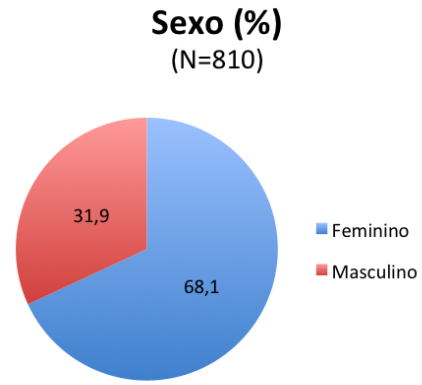

Escolaridade (\%)

$(\mathrm{N}=810)$

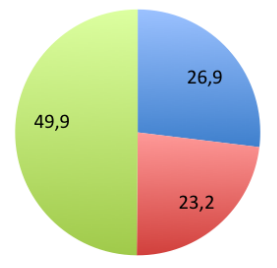

Estado (\%)

$(\mathrm{N}=810)$

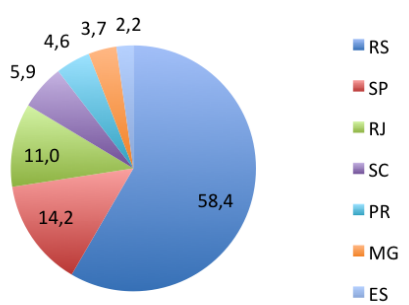

Faixa etária (\%)

$(\mathrm{N}=592)$

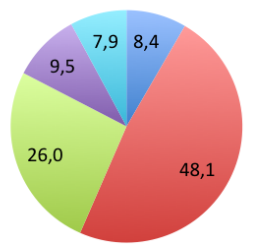

- 16 a 20 anos

- 21 a 30 anos

-31 a 40 anos

41 a 50 anos

Mais de 50 anos

Fonte: Os autores

Como pode ser verificado, o número de respostas válidas ( $\mathrm{N}=592)$ consideradas para a questão "Faixa etária" difere das demais. Isso porque, já durante a aplicação do questionário, foi diagnosticado um problema técnico com a questão, o que fez com que 218 respostas sobre idade fossem perdidas. Dessa forma, sempre que os gráficos apresentarem cruzamentos à faixa etária, o número total de respostas consideradas $(\mathrm{N})$ será diferente do número total de questionários respondidos (810).

\section{Resultados}

Na análise a seguir serão discutidas questões referentes à criação e manutenção de relações amistosas através do uso de serviços de sociabilidade on-line, e à consequente fluidez dessas conversações por diferentes plataformas.

Para a apresentação desses resultados, optamos por organizar a análise dos dados em sete categorias: 1) serviços on-line e seus usos relacionais; 2) particularidades dos usos do Facebook; 3) fazer novos amigos; 4) debater ideias; 5) manter contato com amigos; 6) bater papo; e 7) articulando serviços em uma mesma conversação. 
Serviços on-line e seus usos relacionais

O Facebook apareceu de forma proeminente em relação às demais plataformas em vários dos quesitos analisados, conforme mostra a Figura 2. Como pode ser observado, o serviço representa grande relevância enquanto plataforma para a manutenção de amizades e atividades conversacionais na internet.

- Figura 2 - Principais usos dos serviços

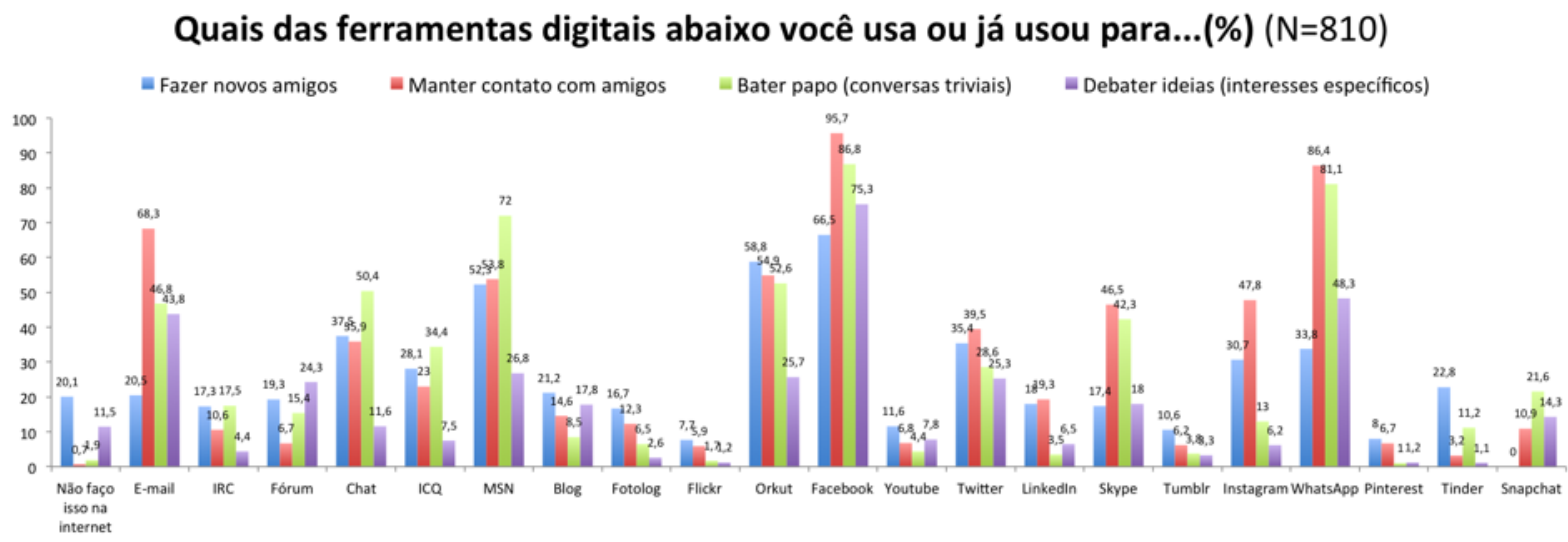

Fonte: Os autores

Com relação ao uso da ferramenta, 95,7\% a utilizam ou já utilizaram para manter contato com os amigos, à frente de serviços como WhatsApp $(86,4 \%) \mathrm{e}$ e-mail (68,3\%). É evidente que não se pode deixar de lembrar do uso combinado entre os serviços, o que será tratado mais adiante neste artigo.

Além disso, outros usos bastante frequentes do Facebook que figuram entre os cinco de maior percentual, como ilustra a Figura 3, são: compartilhar conteúdo de terceiros (94,9\%), publicar conteúdo próprio (92,5\%), ler comentários $(88,6 \%)$ e bater papo $(86,8 \%)$. 


\section{Figura 3 - Usos do Facebook}

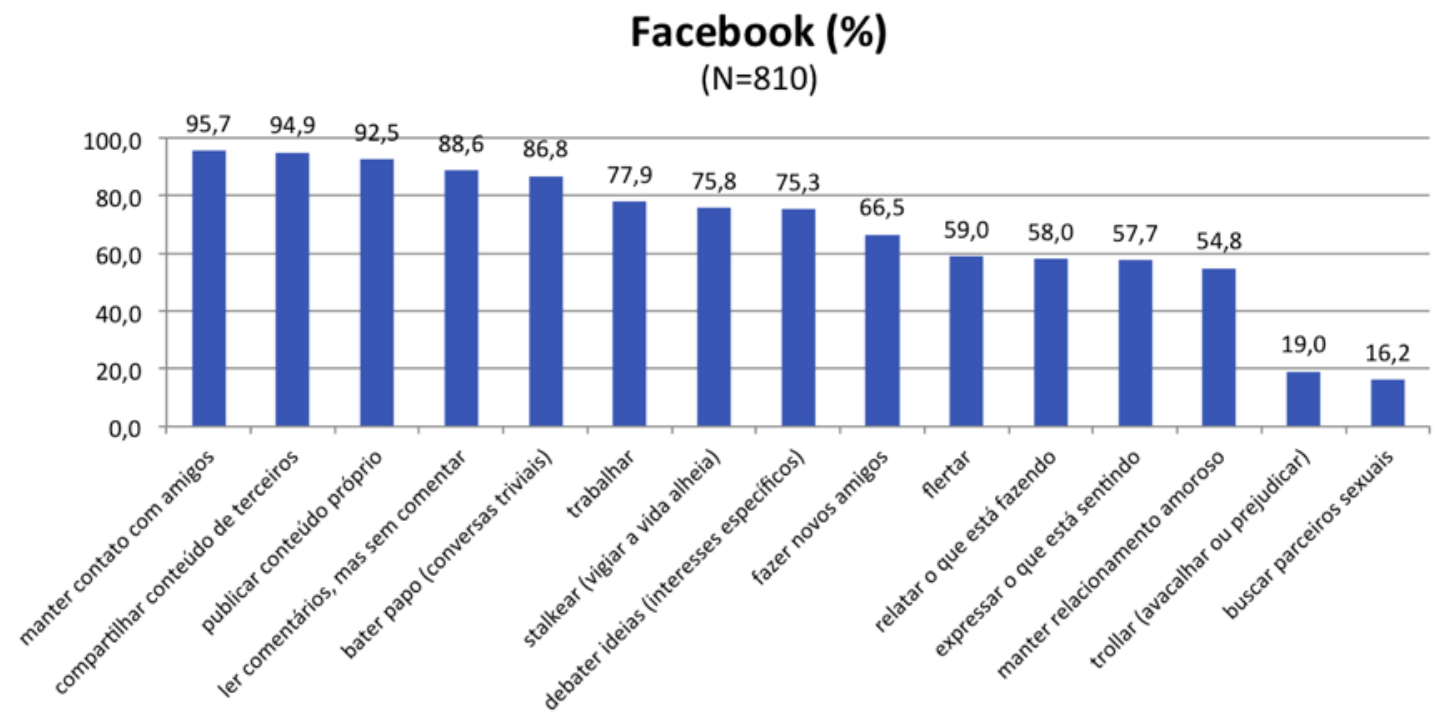

Fonte: Os autores

\section{Particularidades dos usos do Facebook}

Nos casos específicos de utilização do Facebook, foi realizada uma avaliação mais detalhada, por meio de uma escala de gosto para mensurar o grau de preferência de determinados atos no cotidiano dos respondentes. Assim, a partir da questão "O que você gosta de fazer no Facebook?", e através de uma escala gradativa, foram obtidos os seguintes resultados (Figura 4):

\section{Figura 4 - Usos preferenciais do Facebook}

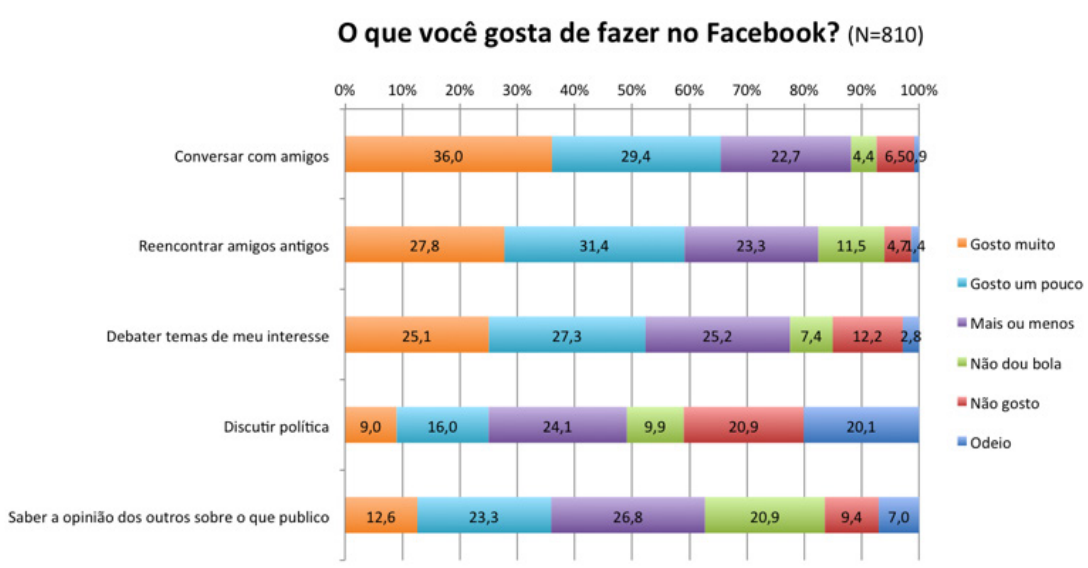

Fonte: Os autores 
"Conversar com amigos" é um dos usos da ferramenta que agrada muito a $36 \%$ dos respondentes, enquanto $29,4 \%$ "gostam um pouco". Ou seja, mais da metade das respostas $(65,4 \%)$ apontam para tal aspecto relacional do site. Com relação ao reencontro de amigos antigos pela rede, $27,8 \%$ dos usuários "gostam muito" e 31,4\% "gostam um pouco" de reencontrar amizades antigas, demonstrando que o serviço tem um papel importante na formação e reforço de laços afetivos.

\section{Fazer novos amigos}

O Facebook também foi o mais citado na questão «Fazer novos amigos», que incluía todos os serviços avaliados, com 66,5\% das respostas (Figura 5). 0 orkut, predecessor do Facebook na preferência dos brasileiros, aparece logo em seguida, com 58,8\% (lembrando que o cerne da questão é: você usa ou já utilizou determinado serviço, o que justifica a presença do site mesmo após a sua desativação). O MSN ocupa a terceira posição, com 52,3\% e os chats (salas de bate-papo) foram lembrados com $37,5 \%$ das respostas. É importante ressaltar que $20,1 \%$ dos respondentes afirmam "não fazer isso na internet".

Os primeiros estudos sobre sites de redes sociais apontam que as pessoas preferiam usar tais serviços para articular relacionamentos já existentes a formar novas amizades, sendo que resultado semelhante foi encontrado por Elisson e Boyd (2013). De toda forma, a Figura 5 revela que uma parcela significativa de nossos respondentes faz ou já fez novos amigos on-line. Como os serviços descontinuados MSN e orkut foram muito populares no Brasil (e de baixo impacto em outros países), podemos apontar que a prática de fazer novos amigos online acompanha a história on-line do brasileiro e atravessa diversas tecnologias.

\section{Figura 5 - Fazer novos amigos}

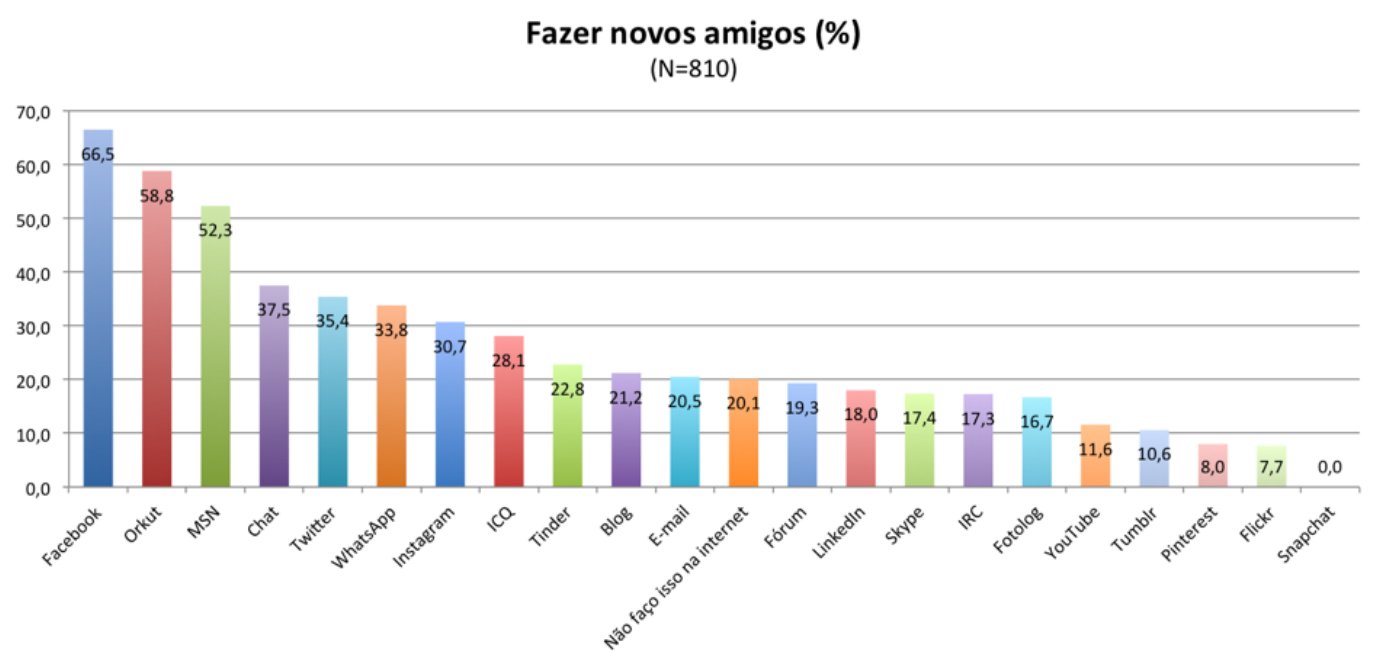

Fonte: Os autores 


\section{Debater ideias}

O debate de ideias e discussões a respeito de interesses específicos são típicos do processo conversacional. Os temas de interesse podem ser responsáveis pela geração e manutenção de novas amizades ou até o seu rompimento por divergências. Nesse sentido, com relação à interação com as ferramentas avaliadas, é possível associar esse debate ao uso de páginas específicas e grupos temáticos. Como ilustra a Figura $6,75,3 \%$ dos respondentes utilizam ou já utilizaram o Facebook para tal prática (lembrando que, na escala de gosto, ilustrada na Figura 4, 27,3\% afirmaram "gostar um pouco", 25,1\% "gostar muito" e $25,2 \%$ gostar "mais ou menos" do debate de temas de interesse). O WhatsApp foi citado por $48,3 \%$, enquanto o e-mail foi a escolha de $43,8 \%$ dos respondentes. Com percentuais muito próximos também foram citados os usos do MSN (26,8\%), orkut (25,7\%) e Twitter (25,3\%). Os fóruns, ambientes inicialmente criados como espaço de debates de interesses específicos, foram mencionados por $24,3 \%$ dos respondentes.

\section{Figura 6 - Debater ideias}

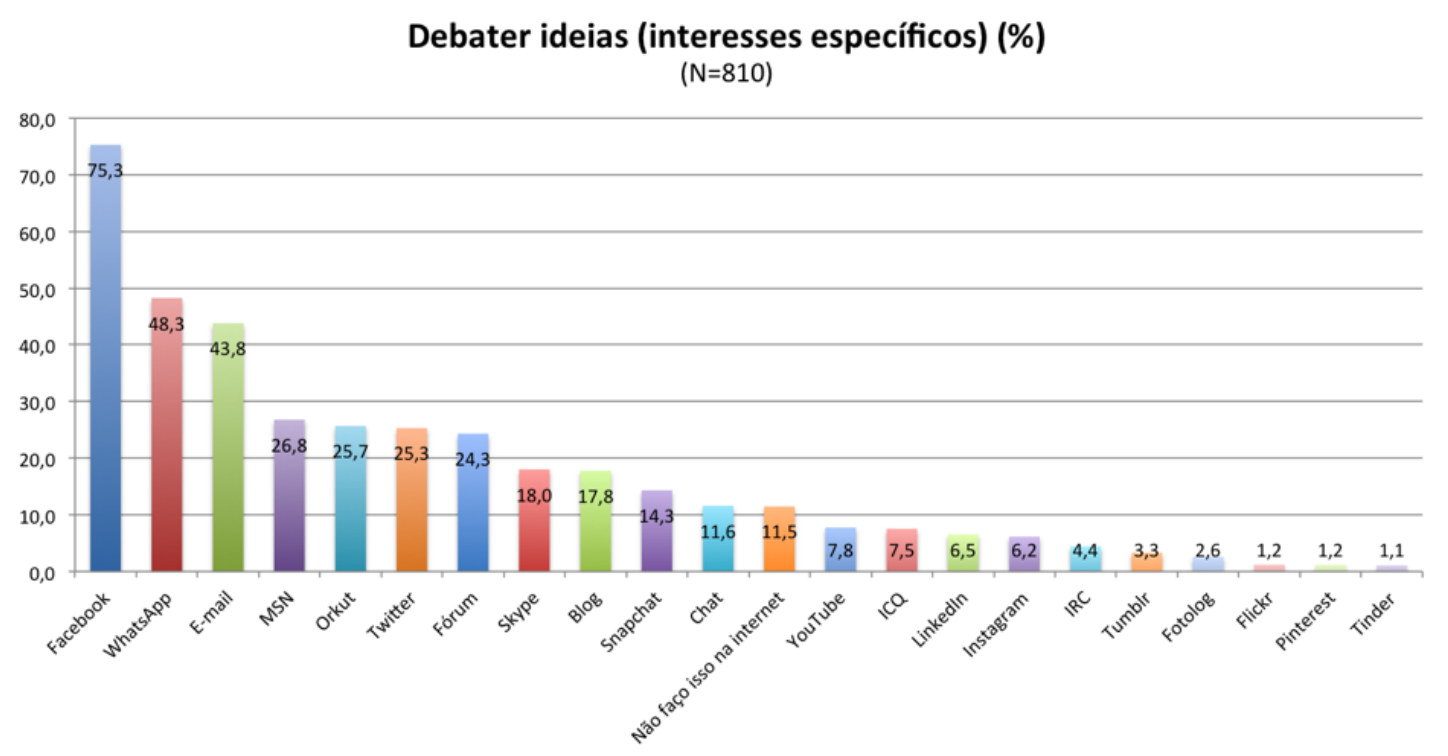

Fonte: Os autores

\section{Manter contato com os amigos}

De modo geral (Figura 7), as ferramentas escolhidas pelos respondentes para manter contato com os amigos que apresentaram maior percentual foram Faceboook (95,7\%), WhatsApp (86,4\%), e-mail (68,3\%), orkut (54,9\%), MSN (53,8\%). Como apenas 0,7\% afirmaram "não fazer isso na internet", percebe-se que estar 
em contato com amigos é um dos principais interesses de nossos respondentes ao conectar-se à internet. Isso demonstra a relevância de pesquisas que visam compreender como tal processo se dá. Vale apontar que a fase qualitativa de nossa pesquisa buscará aprofundar o tema através de entrevistas e grupos focais.

\section{Figura 7 - Manter contato com amigos}

\section{Manter contato com amigos (\%)}

$(\mathrm{N}=810)$

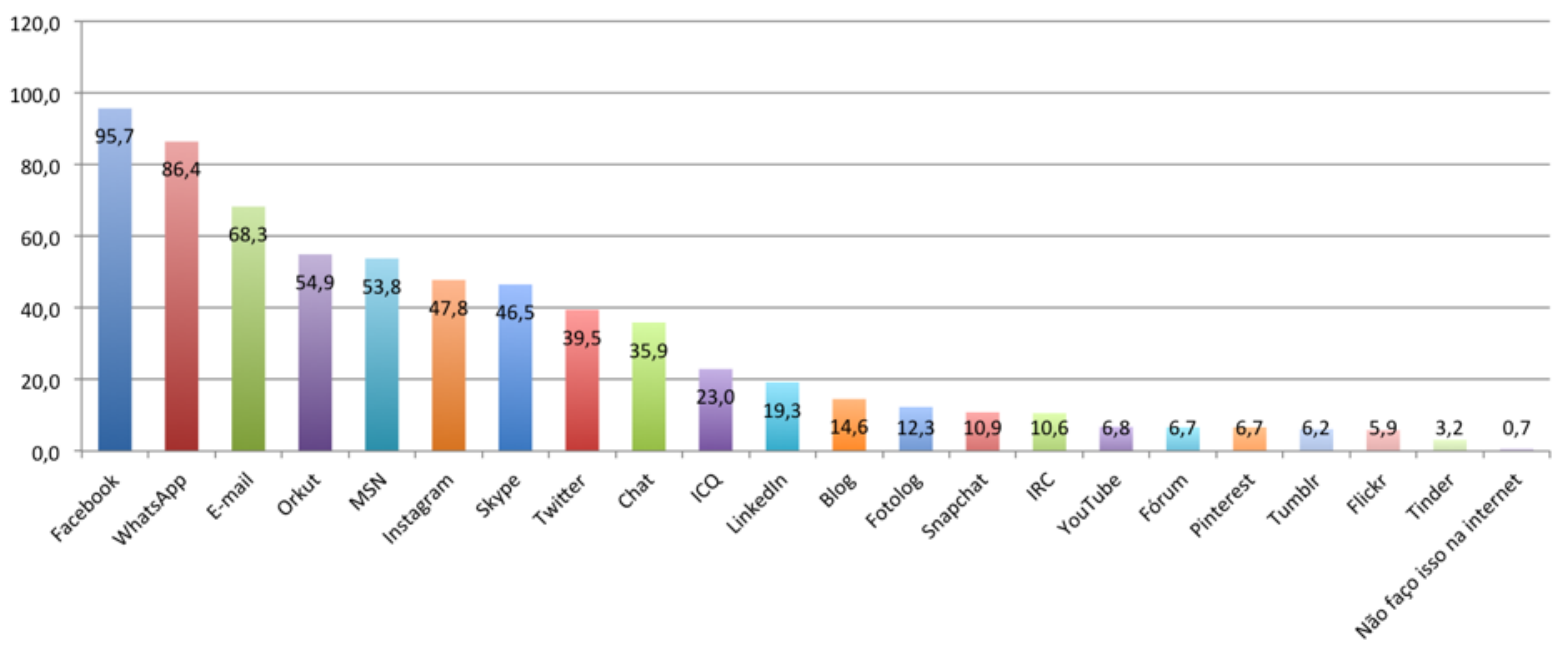

Fonte: Os autores

ATabela 1 trazo detalhamento do cruzamento da questão "Manter contato com os amigos" com aspectos como sexo, faixa etária e ferramentas apontadas pelos respondentes. Com relação ao Facebook, a ferramenta que conta com os percentuais mais elevados desta pesquisa, $95,7 \%$ dos respondentes do sexo feminino disseram utilizá-lo ou já ter utilizado para manter contato com os amigos. Já os respondentes do sexo masculino atingiram o percentual de $95,5 \%$ para o uso com a mesma finalidade. O WhatsAppé a ferramenta citada por $87,2 \%$ das mulheres e por $86 \%$ dos homens da pesquisa. Já o percentual de homens que utilizam ou já utilizaram o e-mail (69\%) como forma de manter contato com os amigos é maior do que o de mulheres (65,3\%). É possível perceber que a diferença em termos percentuais na maioria das ferramentas é mínima, mas em algumas a diferença chama atenção, como na utilização do "Fórum" (3,3\% das mulheres e $13 \%$ dos homens), do Pinterest ( $8,7 \%$ das mulheres e $2,5 \%$ dos homens) e do Snapchat (9,2\% mulheres e 13,5\% homens). Embora não seja o foco principal deste artigo, essas diferenças apontam aspectos das próprias redes e a 
sua relação com os usuários. O Pinterest, por exemplo, apresenta características de curadoria e colecionismo, muito ligados à imaginação e subjetividade, o que o leva a ter um público majoritariamente feminino (Barros, 2015).

Com relação à faixa etária, a maior parte dos respondentes da questão encontra-se entre os 21 e 30 anos. Destes, 96,5\% utilizam o Facebook para a manutenção de contato com os amigos, enquanto na faixa dos 41 a 50 anos o percentual de uso da ferramenta sobe para 98,2\% e acima de 50 anos, 93,6\%. 0 menor percentual de uso do Facebook está entre os jovens de 16 a 20 anos, 92\%.

Com relação ao WhatsApp, o percentual de uso decresce na medida em que a faixa etária se eleva, como demonstra a Tabela 1. Dos 16 aos 20, a utilização pelos respondentes é de $92 \%$, e, se observarmos o outro extremo - mais de 50 anos - o número cai para $63,8 \%$ dos respondentes. No caso da utilização do e-mail, o fenômeno é inverso. Apenas 44\% dos respondentes na faixa etária dos 16 aos 20 anos utiliza ou utilizou o e-mail para manter contato com amigos, enquanto $85,1 \%$ dos respondentes com mais de 50 anos disseram utilizar a ferramenta. É possível observar também a importância da questão geracional nos usos dos artefatos, como está explícito no fato de que os mais jovens, da faixas etária de 16 a 20 anos não utilizaram o ICQ e o IRC para manter contato com os amigos. Ou ainda, como aponta a tabela 1, as faixas de 41 a 50 anos, ou mais de 50, não assinalaram o uso do Tinder.

- Tabela 1 - Manter contato com amigos

\begin{tabular}{|c|c|c|c|c|c|c|c|c|c|c|c|c|c|c|c|c|}
\hline \multirow{3}{*}{$\begin{array}{l}\text { MANTER CONTATO } \\
\text { COM AMIGOS }\end{array}$} & \multirow{2}{*}{\multicolumn{2}{|c|}{ Total }} & \multicolumn{4}{|c|}{ Sexo } & \multicolumn{10}{|c|}{ Faixa Etária (anos) } \\
\hline & & & \multicolumn{2}{|c|}{ Feminino } & \multicolumn{2}{|c|}{ Masculino } & \multicolumn{2}{|c|}{16 a 20} & \multicolumn{2}{|c|}{21 a 30} & \multicolumn{2}{|c|}{31 a 40} & \multicolumn{2}{|c|}{41 a 50} & \multicolumn{2}{|c|}{ Mais de 50} \\
\hline & $\mathrm{n}$ & $\%$ & $n$ & $\%$ & $n$ & $\%$ & $\mathrm{n}$ & $\%$ & $\mathrm{n}$ & $\%$ & $n$ & $\%$ & $\mathrm{n}$ & $\%$ & $\mathrm{n}$ & $\%$ \\
\hline Facebook & 566 & 95,6 & 375 & 95,7 & 191 & 95,5 & 46 & 92,0 & 275 & 96,5 & 146 & 94,8 & 55 & 98,2 & 44 & 93,6 \\
\hline WhatsApp & 514 & 86,8 & 342 & 87,2 & 172 & 86,0 & 46 & 92,0 & 255 & 89,5 & 135 & 87,7 & 48 & 85,7 & 30 & 63,8 \\
\hline E-mail & 394 & 66,6 & 256 & 65,3 & 138 & 69,0 & 22 & 44,0 & 171 & 60,0 & 116 & 75,3 & 45 & 80,4 & 40 & 85,1 \\
\hline Orkut & 328 & 55,4 & 217 & 55,4 & 111 & 55,5 & 31 & 62,0 & 176 & 61,8 & 87 & 56,5 & 22 & 39,3 & 12 & 25,5 \\
\hline MSN & 322 & 54,4 & 220 & 56,1 & 102 & 51,0 & 30 & 60,0 & 177 & 62,1 & 79 & 51,3 & 19 & 33,9 & 17 & 36,2 \\
\hline Instagram & 288 & 48,6 & 214 & 54,6 & 74 & 37,0 & 31 & 62,0 & 160 & 56,1 & 69 & 44,8 & 17 & 30,4 & 11 & 23,4 \\
\hline Skype & 265 & 44,8 & 170 & 43,4 & 95 & 47,5 & 20 & 40,0 & 142 & 49,8 & 64 & 41,6 & 21 & 37,5 & 18 & 38,3 \\
\hline Twitter & 232 & 39,2 & 147 & 37,5 & 85 & 42,5 & 32 & 64,0 & 110 & 38,6 & 62 & 40,3 & 17 & 30,4 & 11 & 23,4 \\
\hline Chat & 211 & 35,6 & 143 & 36,5 & 68 & 34,0 & 28 & 56,0 & 114 & 40,0 & 47 & 30,5 & 14 & 25,0 & 8 & 17,0 \\
\hline ICQ & 131 & 22,1 & 73 & 18,6 & 58 & 29,0 & 0 & 0,0 & 62 & 21,8 & 50 & 32,5 & 12 & 21,4 & 7 & 14,9 \\
\hline Linkedln & 114 & 19,3 & 72 & 18,4 & 42 & 21,0 & 3 & 6,0 & 51 & 17,9 & 38 & 24,7 & 13 & 23,2 & 9 & 19,1 \\
\hline Blog & 87 & 14,7 & 55 & 14,0 & 32 & 16,0 & 2 & 4,0 & 42 & 14,7 & 27 & 17,5 & 8 & 14,3 & 8 & 17,0 \\
\hline Fotolog & 70 & 11,8 & 58 & 14,8 & 12 & 6,0 & 2 & 4,0 & 53 & 18,6 & 12 & 7,8 & 1 & 1,8 & 2 & 4,3 \\
\hline Snapchat & 63 & 10,6 & 36 & 9,2 & 27 & 13,5 & 13 & 26,0 & 33 & 11,6 & 12 & 7,8 & 2 & 3,6 & 3 & 6,4 \\
\hline IRC & 61 & 10,3 & 34 & 8,7 & 27 & 13,5 & 0 & 0,0 & 34 & 11,9 & 22 & 14,3 & 3 & 5,4 & 2 & 4,3 \\
\hline YouTube & 40 & 6,8 & 25 & 6,4 & 15 & 7,5 & 5 & 10,0 & 19 & 6,7 & 9 & 5,8 & 3 & 5,4 & 4 & 8,5 \\
\hline Fórum & 39 & 6,6 & 13 & 3,3 & 26 & 13,0 & 2 & 4,0 & 21 & 7,4 & 8 & 5,2 & 5 & 8,9 & 3 & 6,4 \\
\hline Pinterest & 39 & 6,6 & 34 & 8,7 & 5 & 2,5 & 2 & 4,0 & 21 & 7,4 & 11 & 7,1 & 0 & 0,0 & 5 & 10,6 \\
\hline Tumblr & 34 & 5,7 & 28 & 7,1 & 6 & 3,0 & 15 & 30,0 & 15 & 5,3 & 3 & 1,9 & 0 & 0,0 & 1 & 2,1 \\
\hline Flickr & 31 & 5,2 & 24 & 6,1 & 7 & 3,5 & 0 & 0,0 & 16 & 5,6 & 11 & 7,1 & 1 & 1,8 & 3 & 6,4 \\
\hline Tinder & 20 & 3,4 & 14 & 3,6 & 6 & 3,0 & 3 & 6,0 & 13 & 4,6 & 4 & 2,6 & 0 & 0,0 & 0 & 0,0 \\
\hline Não faço isso na internet & 4 & 0,7 & 4 & 1,0 & 0 & 0,0 & 1 & 2,0 & 1 & 0,4 & 2 & 1,3 & 0 & 0,0 & 0 & 0,0 \\
\hline TOTAL & 592 & 100,0 & 392 & 100,0 & 200 & 100,0 & 50 & 100,0 & 285 & 100,0 & 154 & 100,0 & 56 & 100,0 & 47 & 100,0 \\
\hline
\end{tabular}

Fonte: Os autores 


\section{Bater papo}

Quanto à questão sobre "bater papo (conversas triviais)" na internet, a Figura 8 mostra que o Facebook continua como a principal escolha $(86,8 \%)$, seguido pelo WhatsApp (81,1\%), MSN (72\%), orkut (52,6\%), Chat (50,4\%), E-mail $(46,8 \%)$.

\section{Figura 8 - Bater papo}

\section{Bater papo (conversas triviais) (\%)}

$(\mathrm{N}=810)$

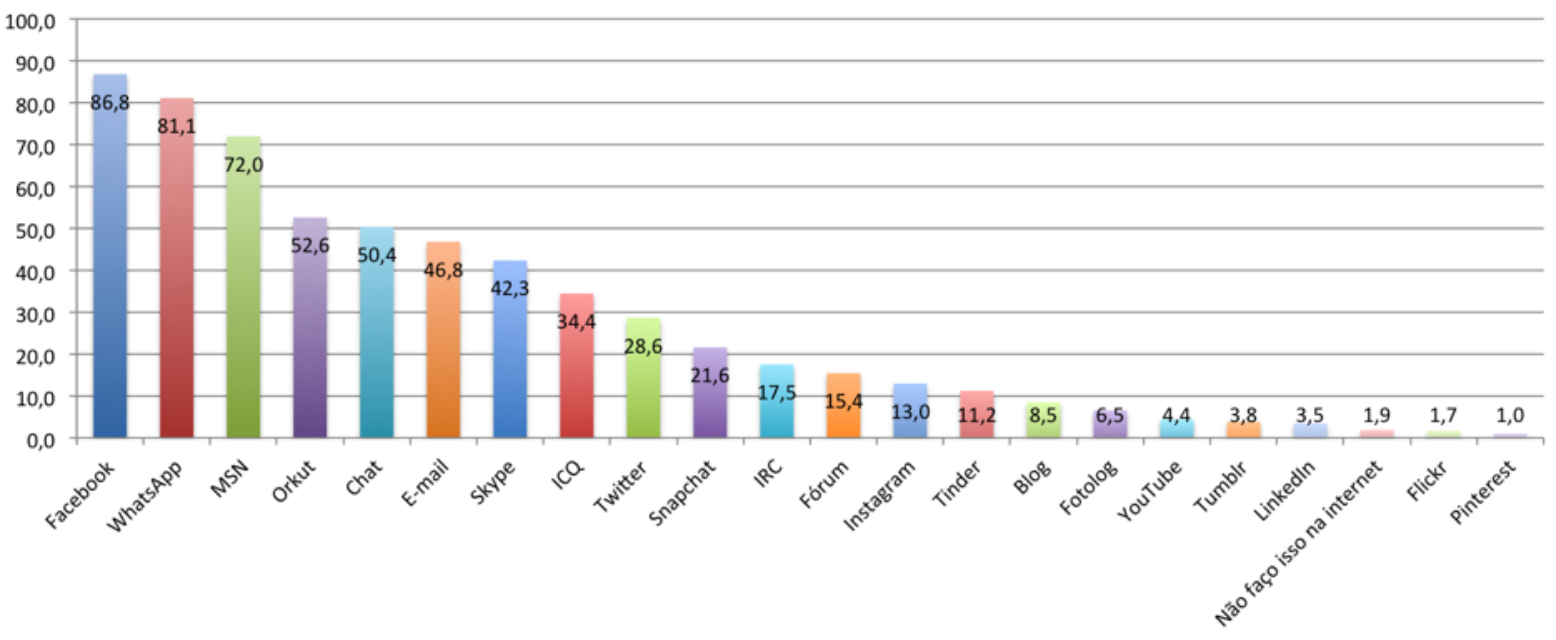

Fonte: Os autores

A Tabela 2 relaciona a questão "Bater papo (conversas triviais)" com aspectos de faixa etária, sexo e as ferramentas utilizadas pelo público da pesquisa. Nesse caso, o Facebook foi a ferramenta citada por $88 \%$ das mulheres e $87 \%$ dos homens para bater papo e/ou ter conversas triviais na internet. Na sequência, como demonstra a tabela 2, estão o WhatsApp, opção de $82,9 \%$ das mulheres e $79,5 \%$ dos homens. Na terceira posição, o $M S N$, opção assinalada por $73 \%$ das mulheres e $70 \%$ dos homens. O orkut foi lembrado por $53,3 \%$ dos respondentes do sexo feminino e $54,5 \%$ do sexo masculino. O e-mail, ao contrário da tabela que demonstra as opções dos respondentes para manter o contato com amigos, está na sexta posição, com a utilização de $44,9 \%$ dos respondentes do sexo feminino e $52,5 \%$ dos respondentes do sexo masculino. Essa diferença nas respostas das questões "Bater papo" e "Manter contato com amigos" (Tabelas 1 e 2) torna evidente os usos específicos e apropriações das ferramentas pelos respondentes, independente do sexo declarado. A partir dos dados explicitados acima, por exemplo, pode-se inferir que o e-mail não se torna a principal escolha quando a intenção é o bate-papo e a conversação imediata. Como veremos a seguir, na seção que mostra as opções de combinações utilizadas pelos respondentes, em 
um dos casos o e-mail foi preterido em função de sua assincronia. Conforme respondido em nosso questionário, "por não ser em tempo real" o e-mail não parecia ser conveniente para uma interação que iniciou no Twitter, passou pelo e-mail e continuou no Skype. O mesmo respondente justificou ter trocado o Twitter pelo Skype durante tal conversa em virtude da "limitação de caracteres" do primeiro. Assim, de acordo com a situação pode-se perceber a opção do uso em conjunto ou alternado do e-mail com outros serviços de comunicação, como apontam os estudos de Madianou e Miller (2013).

Assim como na Tabela 1, com relação ao sexo dos respondentes e as ferramentas utilizadas, os percentuais não são muito discrepantes, embora haja maior número de respondentes do sexo feminino. $\mathrm{O}$ uso de fóruns para bater papo e conversas triviais segue com o maior número de usuários do sexo masculino (homens: $24,5 \%$ e mulheres: 11,5\%), assim como no Tinder (homens: 13\% e mulheres: 10,5\%) e no Twitter (homens: $38 \%$, mulheres: $26,3 \%$ ).

Com relação à faixa etária, o Facebook é utilizado por $92,3 \%$ dos indivíduos na faixa dos 21 a 30 anos, seguidos pelos jovens de 16 a 20 anos, cujo uso foi assinalado por $92 \%$ dos respondentes. Já o WhatsApp é ou já foi utilizado por $85,1 \%$ dos pesquisados que têm entre 31 e 40 anos, se tornando ferramenta principal dessa faixa etária. Também é importante ressaltar a forte presença do Facebook entre os indivíduos com mais de 50 anos que responderam à pesquisa: $80,9 \%$ usam ou já utilizaram o Facebook para bate-papo ou conversas triviais.

Tabela 2 - Bater papo (conversas triviais)

\begin{tabular}{|c|c|c|c|c|c|c|c|c|c|c|c|c|c|c|c|c|}
\hline \multirow{3}{*}{$\begin{array}{c}\text { BATER PAPO } \\
\text { (CONVERSAS TRIVIAIS) }\end{array}$} & \multirow{2}{*}{\multicolumn{2}{|c|}{ Total }} & \multicolumn{4}{|c|}{ Sexo } & \multicolumn{10}{|c|}{ Faixa Etária (anos) } \\
\hline & & & \multicolumn{2}{|c|}{ Feminino } & \multicolumn{2}{|c|}{ Masculino } & \multicolumn{2}{|c|}{16 a 20} & \multicolumn{2}{|c|}{21 a 30} & \multicolumn{2}{|c|}{31 a 40} & \multicolumn{2}{|c|}{41 a 50} & \multicolumn{2}{|c|}{ Mais de 50} \\
\hline & $\mathrm{n}$ & $\%$ & $n$ & $\%$ & $\mathrm{n}$ & $\%$ & $\mathrm{n}$ & $\%$ & $n$ & $\%$ & $\mathrm{n}$ & $\%$ & $\mathrm{n}$ & $\%$ & $n$ & $\%$ \\
\hline Facebook & 519 & 87,7 & 345 & 88,0 & 174 & 87,0 & 46 & 92,0 & 263 & 92,3 & 128 & 83,1 & 44 & 78,6 & 38 & 80,9 \\
\hline WhatsApp & 484 & 81,8 & 325 & 82,9 & 159 & 79,5 & 42 & 84,0 & 242 & 84,9 & 131 & 85,1 & 40 & 71,4 & 29 & 61,7 \\
\hline MSN & 426 & 72,0 & 286 & 73,0 & 140 & 70,0 & 35 & 70,0 & 218 & 76,5 & 121 & 78,6 & 30 & 53,6 & 22 & 46,8 \\
\hline Orkut & 318 & 53,7 & 209 & 53,3 & 109 & 54,5 & 30 & 60,0 & 175 & 61,4 & 78 & 50,6 & 21 & 37,5 & 14 & 29,8 \\
\hline Chat & 293 & 49,5 & 183 & 46,7 & 110 & 55,0 & 25 & 50,0 & 151 & 53,0 & 81 & 52,6 & 21 & 37,5 & 15 & 31,9 \\
\hline E-mail & 281 & 47,5 & 176 & 44,9 & 105 & 52,5 & 14 & 28,0 & 121 & 42,5 & 95 & 61,7 & 28 & 50,0 & 23 & 48,9 \\
\hline Skype & 247 & 41,7 & 154 & 39,3 & 93 & 46,5 & 18 & 36,0 & 122 & 42,8 & 69 & 44,8 & 22 & 39,3 & 16 & 34,0 \\
\hline ICQ & 199 & 33,6 & 112 & 28,6 & 87 & 43,5 & 0 & 0,0 & 87 & 30,5 & 84 & 54,5 & 17 & 30,4 & 11 & 23,4 \\
\hline Twitter & 179 & 30,2 & 103 & 26,3 & 76 & 38,0 & 25 & 50,0 & 87 & 30,5 & 47 & 30,5 & 13 & 23,2 & 7 & 14,9 \\
\hline Snapchat & 129 & 21,8 & 88 & 22,4 & 41 & 20,5 & 28 & 56,0 & 78 & 27,4 & 17 & 11,0 & 4 & 7,1 & 2 & 4,3 \\
\hline IRC & 95 & 16,0 & 51 & 13,0 & 44 & 22,0 & 0 & 0,0 & 48 & 16,8 & 37 & 24,0 & 7 & 12,5 & 3 & 6,4 \\
\hline Fórum & 94 & 15,9 & 45 & 11,5 & 49 & 24,5 & 7 & 14,0 & 44 & 15,4 & 26 & 16,9 & 11 & 19,6 & 6 & 12,8 \\
\hline Instagram & 83 & 14,0 & 49 & 12,5 & 34 & 17,0 & 6 & 12,0 & 39 & 13,7 & 28 & 18,2 & 5 & 8,9 & 5 & 10,6 \\
\hline Tinder & 67 & 11,3 & 41 & 10,5 & 26 & 13,0 & 14 & 28,0 & 36 & 12,6 & 15 & 9,7 & 2 & 3,6 & 0 & 0,0 \\
\hline Blog & 56 & 9,5 & 29 & 7,4 & 27 & 13,5 & 3 & 6,0 & 23 & 8,1 & 21 & 13,6 & 6 & 10,7 & 3 & 6,4 \\
\hline Fotolog & 40 & 6,8 & 25 & 6,4 & 15 & 7,5 & 0 & 0,0 & 29 & 10,2 & 9 & 5,8 & 0 & 0,0 & 2 & 4,3 \\
\hline YouTube & 33 & 5,6 & 14 & 3,6 & 19 & 9,5 & 3 & 6,0 & 16 & 5,6 & 9 & 5,8 & 2 & 3,6 & 3 & 6,4 \\
\hline Tumblr & 24 & 4,1 & 12 & 3,1 & 12 & 6,0 & 6 & 12,0 & 11 & 3,9 & 7 & 4,5 & 0 & 0,0 & 0 & 0,0 \\
\hline Linkedln & 21 & 3,5 & 13 & 3,3 & 8 & 4,0 & 0 & 0,0 & 4 & 1,4 & 10 & 6,5 & 3 & 5,4 & 4 & 8,5 \\
\hline Flickr & 13 & 2,2 & 5 & 1,3 & 8 & 4,0 & 0 & 0,0 & 8 & 2,8 & 5 & 3,2 & 0 & 0,0 & 0 & 0,0 \\
\hline Não faço isso na internet & 10 & 1,7 & 6 & 1,5 & 4 & 2,0 & 0 & 0,0 & 3 & 1,1 & 1 & 0,6 & 4 & 7,1 & 2 & 4,3 \\
\hline Pinterest & 7 & 1,2 & 4 & 1,0 & 3 & 1,5 & 0 & 0,0 & 3 & 1,1 & 2 & 1,3 & 0 & 0,0 & 2 & 4,3 \\
\hline TOTAL & 592 & 100,0 & 392 & 100,0 & 200 & 100,0 & 50 & 100,0 & 285 & 100,0 & 154 & 100,0 & 56 & 100,0 & 47 & 100,0 \\
\hline
\end{tabular}

Fonte: Os autores 
De forma geral pode-se perceber um possível trânsito de usuários pela rede, seja pelo fim de uma ferramenta, como o orkut, seja pela perda de popularidade, como o MSN (antes de ser descontinuado), ou ainda a necessidade de utilizar uma ferramenta mais popular, como o Facebook. É possível que o uso de várias ferramentas pela maioria dos respondentes (como as Tabelas 1 e 2 evidenciam) possa ser o indício de que as pessoas buscam soluções para as suas necessidades comunicacionais, o que frequentemente resulta na combinação de múltiplas plataformas e, consequentemente, em conversações mais fluidas.

\section{Articulando serviços em uma mesma conversação}

Diante dos indícios de que as pessoas costumam utilizar diversos serviços on-line para manter amizades e conversar, buscamos avaliar o número médio de meios digitais marcados pelos respondentes nas questões "Manter contato com amigos" e "Bater papo (conversas triviais)". Com o intuito de observar apenas serviços populares em 2015, para esta aferição foram considerados apenas e-mail, Facebook, Twitter, Skype, Instagram, WhatsApp, Snapchat e Tinder.

\section{Figura 9 - Combinação de serviços}

\section{Quantidade de serviços utilizados ( $\mathrm{N}=810)$}

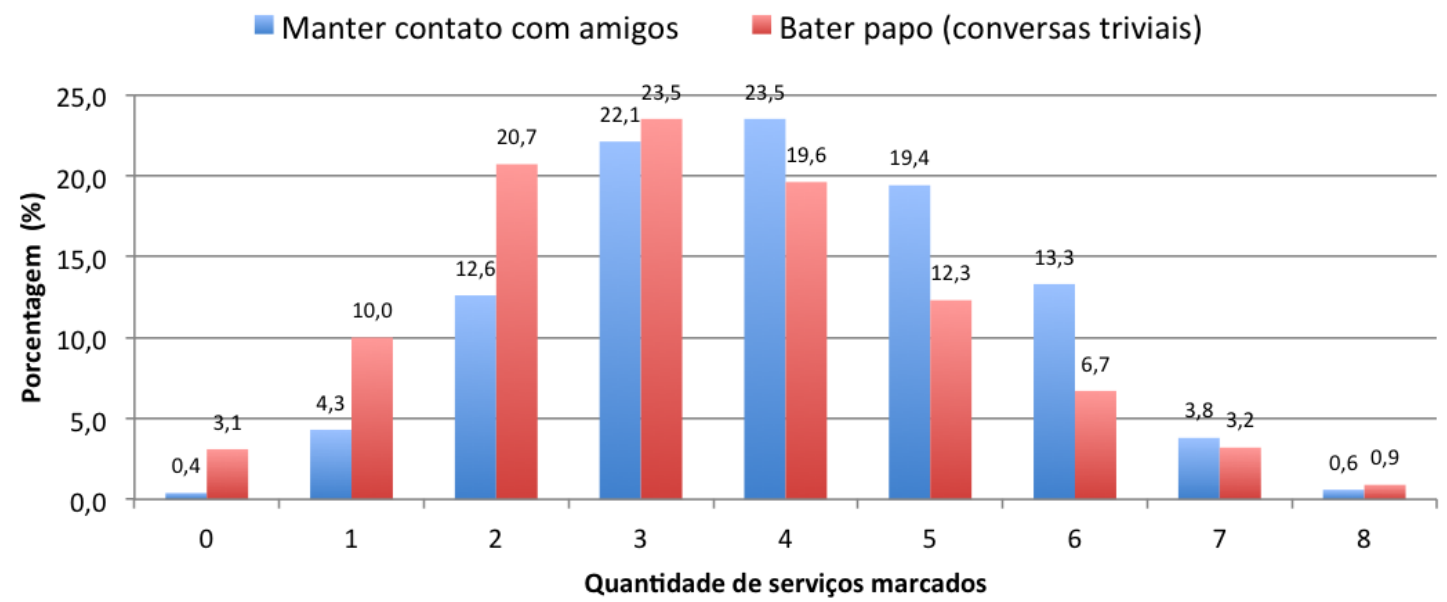

Fonte: Os autores

Como mostra a Figura 9, para manter contato com amigos, 95,3\% afirmaram usar mais de um serviço para esse fim (3,98 em média): 12,6\% usam dois dos serviços listados, 22,1\% usam três, 23,5\% usam quatro, 19,4\% usam cinco, $13,3 \%$ usam seis, 3,8\% usam sete e $0,6 \%$ disseram usar todos aqueles meios listados. Para bater papo na internet, $86,9 \%$ responderam usar mais de um meio digital (média de 3,31): 20,7\% usam dois serviços on-line para conversas 
triviais, 23,5\% usam três, 19,6\% usam quatro, 12,3\% usam cinco, 6,7\% usam seis, 3,2 usam sete e 0,9 usam os oito listados.

No intuito de buscar mais elementos sobre a combinação de diferentes serviços para a manutenção de conversações on-line, nosso questionário trazia a seguinte questão: "Você já usou mais de uma ferramenta on-line para continuar uma mesma conversa?". Dentre os respondentes, 77\% afirmaram que sim. Estes foram então convidados a descrever "quais ferramentas foram combinadas em uma mesma conversa (mesmo assunto) e o porquê". O preenchimento da questão aberta não era obrigatório, mas 551 respostas foram recebidas - ainda que nem todas elas tenham seguido a solicitação de citar outras ferramentas utilizadas e as razões que motivaram o trânsito entre essas plataformas.

Para muitos dos respondentes, as combinações de serviços para dar continuidade a uma mesma conversação parecem fazer parte de seu cotidiano. Além do gráfico visto anteriormente, outra evidência disso é a presença de expressões como "às vezes", assim como "normalmente" e "ultimamente" que foram recorrentes nas respostas obtidas.

A análise da tabulação das respostas abertas obtidas nos permitiu reconhecer que a fluidez nas conversações on-line está associada a uma série de fatores: affordances do serviço de comunicação (recursos oferecidos, interface, etc); affordances do aparato técnico (hardware, qualidade da conexão, etc.); o entorno off-line onde os interagentes se encontram (trabalho, na rua, em casa, na presença de outras pessoas, horário, etc.); o tema e conteúdo da conversa, seu formato e sua finalidade; e quem são os interlocutores (um amigo, todos os seguidores do Twitter, colega de trabalho, família, etc.). A seguir, desdobraremos cada um desses fatores através da análise de algumas respostas concedidas.

Com relação às affordances do serviço, observamos que as funcionalidades disponíveis aos participantes do encontro on-line repercutem em suas escolhas de qual serviço se presta melhor à conversação em andamento. Veja-se por exemplo esta resposta: "Conheço a pessoa pelo Tinder e depois vamos pra outras redes". Segundo a respondente, o deslocamento para o WhatsApp ou Facebook se deve ao fato de serem "mais fáceis de conversar e trocar conteúdos". Em outra situação, uma interagente afirmou que sua conversa iniciou por Twitter, transitou pelo e-mail e teve sua continuação através do Skype. Como ela buscava uma ferramenta para bater papo, o Twitter "com sua limitação de caracteres" e a assincronia do e-mail ("por não ser em tempo real") não lhe pareciam convenientes naquele momento.

Como se mostrou anteriormente, Facebook e WhatsApp são frequentemente combinados para uma mesma conversa pelos interagentes. Conforme as respostas colhidas, a possibilidade de envio de áudio pelo WhatsApp 
foi um recurso bastante citado quando o serviço é escolhido. Já o Facebook, por possuir o bate-papo em conjunto com o feed de notícias e timeline, favorece o compartilhamento de links e arquivos. Esse aspecto se torna ainda mais evidente quando o interagente utiliza o Facebook no computador.

As affordances do aparato técnico também contribuem para a fluidez das conversações. Respondentes afirmaram que muitas vezes preferem transferir a conversa do smartphone para o computador "pela facilidade de digitação", ou o inverso, "por questões de mobilidade geralmente". Enquanto o Facebook surgiu como um site para a Web, o WhatsApp é um serviço nativamente mobile embora ambos passaram a ter versões para outros suportes. Uma interagente, por exemplo, respondeu que transitava do WhatsApp para o Facebook à medida que trocava de dispositivo: "Estava com ambos conectados e conforme me locomovia pela casa, alternava o meio para responder e continuar a conversa. Ambos, eu e a pessoa com quem conversava, estavámos fazendo isso". Por meio das respostas obtidas, constatou-se que ao mesmo tempo em que a conversa transcendia serviços específicos, ela também atravessava diferentes hardware.

A questão da conexão é também tecnicamente relevante para a condução de conversações para os brasileiros, visto a discrepância da disponibilidade de tráfego nos planos de pacote de dados para a conexão banda larga e desta última nem sempre apresentar qualidade suficiente para a utilização do serviço: "por razões de conectividade, às vezes dava problema em uma das ferramentas". Os respondentes demonstraram fazer uso de diversas formas de banda larga, por cabo e wireless (como 3G). As melhorias das redes 3G e 4G ampliaram o uso de tecnologias nativamente mobile: "...a conexão da internet ficou ruim e o WhatsApp passou a funcionar melhor". Skype, Hangouts e outros serviços de ligações por vídeo exigem certa qualidade de conexão com a internet, portanto acabam sendo bastante interligados entre si e com outros serviços que exigem menos banda: "a conexão da vídeo-chamada estava com problemas e usei o face ou whats como apoio".

O entorno off-line em que a pessoa se encontra também pode contribuir para a fluidez das conversações on-line. O trânsito pelos serviços para conversações com fins pessoais tem certa ocorrência, por exemplo, quando o interagente chega ou deixa o ambiente de trabalho. Uma respondente afirmou continuar a conversa que mantinha no bate-papo do Facebook para o"hangouts do google, porque o facebook não é tão aceito no ambiente de trabalho quanto o gmail". Por um motivo similar, outro respondente explicou que às vezes sua conversação via WhatsApp é continuada no Facebook: "ela passa para o Facebook por estar no trabalho - e aí fica mais fácil responder via $P C$ em vez de via smartphone". Neste caso, vê-se como o entorno off-line estimula os fluidos 
conversacionais a "escorrer" por entre diferentes serviços de comunicação online (software) e aparatos técnicos (hardware, conexão).

O tema, finalidade e formato da conversa se mostraram também como motivos para seu desdobramento em diversos serviços. Uma respondente afirmou que prefere utilizar email "para escrever textos longos", enquanto outra disse utilizar o Snapchat em conjunto com WhatsApp, pois este último "é melhor para conversas mais longas". Um terceiro afirmou utilizar Twitter e WhatsApp para "recados e coisas breves" e o Facebook caso "a conversa for longa, ou sobre um tema que envolva maior interação". Outro aspecto identificado nas respostas, foi a preferência por certos serviços em detrimento de outros para conversas consideradas íntimas, reservadas ou privadas. Para um respondente, redes como WhatsApp e Facebook proporcionam "um contato mais intimo (sic) "em suas conversações do que o Tinder. Outra pessoa afirmou levar a conversa do Facebook para o WhatsApps "para um contato mais reservado". O envio de conteúdo específico, como arquivos e links que já se localizam em determinado serviço também influenciam para a escolha do serviço "às vezes determinado conteúdo sobre o qual se está falando em uma ferramenta está em outra ferramenta".

As respostas obtidas não deixaram de destacar a importância de quem são os interlocutores na escolha dos serviços on-line. Considerando quem são as pessoas com quem se conversa e de qual é a intensidade do laço entre elas, diferentes serviços on-line podem se mostrar mais adequados. Uma interagente informou que prefere conversar com seus amigos virtuais por serviços que ofereçam bate-papo: "me sinto mais próxima deles em chats como whatsapp e telegram do que falando no facebook nos grupos fechados". Outro fator importante é o acesso ao serviço por todos os participantes do encontro virtual. Uma das respondentes da pesquisa justificou a transferência de uma conversa para o Facebook "porque em uma conversa entre várias pessoas, uma delas não tinha WhatsApp".

O que podemos observar é que esses fatores não são estanques ou isolados, influem e agem uns sobre outros, como também em conjunto com outros. Todos eles vão impactar o desenrolar da conversação, que vai transcender diversos serviços e plataformas. Enquanto o processo comunicacional acontece, o hibridismo dessas associações sociotécnicas acarreta transformações nos fluidos conversacionais (narrativas, modos de expressão, etc.), como também nos próprios interagentes envolvidos. 


\section{Considerações Finais}

A partir do panorama fornecido pela gama de respostas coletadas na fase quantitativa desta pesquisa e da relação com os estudos da área, torna-se possível perceber como alguns dos fatores que compõem as maneiras de se relacionar e as experiências cotidianas em nosso tempo estão vinculados aos usos de serviços de comunicação on-line.

Ainda que o termo "fluidez" seja utilizado por Bauman $(2001,2004)$ para criticar a nova fase das relações contemporâneas - no sentido de serem conexões, frouxas e muitas vezes efêmeras - , quando referimo-nos a "conversações fluidas" buscamos descrever o estado de fluxo constante no qual se encontram as interações on-line. A ideia de fluidez nos parece rica para narrar como as conversações na internet podem ser móveis, como "escorrem" por entre vários tempos e lugares, como se "espalham", como estão continuamente em movimento. Ou seja, aquilo que flui é o que não pode ser apreendido em um só momento, ambiente (on-line ou off-line) ou tecnologia.

Fluidas e híbridas, as conversações on-line combinam serviços digitais de comunicação julgados como mais adequados para a interação em dado momento e segundo certas condições. Em um ambiente polimidiático (Madianou e Miller, 2013), as escolhas dos meios refletem as oportunidades e limitações que os participantes percebem em cada serviço em relação às suas intenções relacionais. Enquanto os fluidos conversacionais circulam por entre os serviços on-line temporariamente escolhidos, os relacionamentos e emoções são atualizados. Mas não apenas os interlocutores humanos modificam-se uns aos outros, pois nestas associações híbridas os agentes não humanos também os fazem fazer coisas (Latour, 2005).

A partir das respostas coletadas nesta fase da pesquisa, pudemos constatar que a fluidez da conversação on-line faz parte do cotidiano das pessoas. Além disso, pudemos identificar diversos fatores associados à fluidez das conversações na internet que nos permitem agora ampliar nossa definição do fenômeno. As conversações fluidas conectam atores, atravessam diversas espacialidades (online e off-line) e temporalidades (sincronia e assincronia) através da articulação de mais de um serviço de comunicação digital para a manutenção de uma mesma conversa, transformando as relações entre os interagentes. Os fluidos conversacionais ocorrem e são transformados não apenas por a) quem fala e b) do que se fala, mas também pelos meios disponíveis e escolhidos em cada momento, em virtude das affordances dos c) serviços de comunicação (software) e d) do aparato técnico (hardware e redes de conexão), além do e) entorno offline. Evidentemente, o conteúdo das conversações e as subjetividades em cena 
são impactados por uma série de questões (sociológicas, filosóficas, linguísticas, discursivas, políticas, etc.) que vão além do escopo deste trabalho.

A perspectiva relacional desta pesquisa não permite que os fluidos conversacionais sejam abordados apenas como uma circulação de mensagens em uma rede técnica. Entre tantos condicionantes epocais, as conversações fluidas e o estado de conexão continuada (always on) transformam significativamente a criação, manutenção e rompimento de relacionamentos. Não apenas o processo de conhecer novas pessoas se torna facilitado através da internet, mas a manutenção de amizades existentes ganha desdobramentos que jamais poderiam ser imaginados pelos primeiros filósofos a refletir sobre o tema. A frequência das conversações triviais (que podem ter grande relevância para a construção da intimidade) e do debate de ideias na internet faculta aos parceiros estar juntos mesmo quando não compartilham tempo e lugar — uma possibilidade significativa diante dos corridos tempos atuais. Tal aspecto pode acelerar a construção da intimidade ou até mantê-la mesmo quando não há recorrência de encontros presenciais.

Claro, a permanente conexão e a possibilidade de conversar a qualquer momento e lugar também tem seu preço, desde estafa cognitiva a dores por esforço repetido. Enquanto computador de bolso conectado à internet, o smartphone permite que mensagens sejam enviadas a qualquer tempo e uma expectativa por uma resposta imediata é criada. Se o estado always on permite que amigos estejam sempre em contato, compromissos profissionais passam também a extrapolar o local e horário de trabalho. Nesse sentido, a possibilidade de manter conversações a qualquer hora pode constituir mais uma exigência desta frenética era.

Finalmente, é preciso reconhecer que uma pesquisa de tal abrangência corre riscos e limitações. O intuito de mapear um histórico dos usos dos serviços de comunicação levou-nos a utilizar perguntas no questionário com o tempo verbal no passado e no presente:"Quais meios você usa ou já usou para...." Nesse sentido, ao marcar certos serviços on-line, o respondente não necessariamente está afirmando que continua a utilizá-los hoje. Apesar do risco envolvido em tal ambiguidade, a formulação da questão permitiu a inclusão de serviços como IRC, orkut, ICQ e MSN que já estiveram muito presentes no cotidiano dos interagentes e na história dos usos dos meios digitais como mediadores de relacionamentos amistosos e profissionais. A fase qualitativa desta pesquisa, que envolverá entrevistas e grupos focais, pretende esclarecer e aprofundar tais aspectos. 


\section{Referências}

BARROS, Carla. "Materialismo digital", consumo e contemplação na rede social Pinterest. Revista ECO-Pós, [S.I.], v. 18, n. 1, p. 120-132, jul. 2015. ISSN 21758689. Disponível em: <https://revistas.ufrj.br/index.php/eco pos/article/ view/1975>. Acesso em: 17 fev. 2016.

BAUMAN. A modernidade líquida. Rio de Janeiro: Zahar, 2001

BAUMAN, Zygmunt. O amor líquido. Rio de Janeiro: Zahar, 2004.

BAUMAN, Z.Zygmunt Bauman - a Amizade Facebook. Youtube [Site], 2013. Disponível em: <https://www.youtube.com/watch?v=5Lm203Q56Wg >. Acesso em: 15 fev. 2016.

BOYD, Dannah; ELLISON, Nicole B. Social network sites: Definition, history, and scholarship: w. Journal of Computer Mediated Communication, v. 13, n. 1, p. 210-230, 2007.

BOYD, Dannah; MARWICK, Alice E. Social privacy in networked publics: Teens' attitudes, practices, and strategies. In: A Decade in Internet Time: Symposium on the Dynamics of the Internet and Society, x, 2011, Anais. 2011.

CHAMBERS, Deborah. Social Media and Personal Relationships: On-line Intimacies and Networked Friendship. Palgrave McMillan, 2013.

ELLISON, Nicole B; BOYD, Danah. Sociality through social network sites. In: Dutton, W. H. (ed.), Oxford University Press Oxford, 2013. p. 151-172.

G1 [Site]. WhatsApp: Justiça concede liminar para restabelecer aplicativo no Brasil. Tecnologia e Games, 2015. Disponível em: <http://g1.globo.com/tecnologia/ noticia/2015/12/whatsapp-justica-concede-liminar-para-restabeleceraplicativo-no-brasil.html>. Acesso em: 12 jul. 2016.

GARTON, Laura; HAYTHORNTHWAITE, Caroline; WELLMAN, Barry. Studying On-line Social Networks. Journal of Computer Mediated Communication, v. 3, n. 1, p. 1-23, 1997.

GERGEN, Kenneth J. The Saturated Self. New York, NY: Basic Books, 2000.

GIBSON, James J. The Theory of Affordances. In: Shaw, Robert; Bransford, John (eds.), Perceiving, Acting, and Knowing. Hoboken, NJ: John Wiley \& Sons Inc., 1977. p. 127-143.

HAYTHORNTHWAITE, Caroline. Social Networks and Internet Connectivity Effects. Information, Communication \& Society, v. 8, n. 2, p. 125-147, 2005. 
JIVANDA, T. Facebook'dead and Buried'as Teens Switch to Snapchat and Whatsapp. The Independent [Site], 2013. Disponível em: <http://www.independent.co.uk/ life-style/gadgets-and-tech/news/facebook-dead-and-buried-as-teens-switchto-snapchat-and-whatsapp-9028208.html>. Acesso em: 15 fev. 2016.

LATOUR, Bruno. Reassembling the Social: An Introduction to Actor-Network-theory. New York: Oxford University Press, 2005.

LEEUWEN, Theo Van. Critical Analysis of Multimodal Discourse(ed.), The Encyclopedia of Applied Linguistics. New Jersey: Blackwell Publishing, 2012.

LENHART, Amanda. Teen, Social Media and Technology Overview 2015. Pew Research Center [Site], 2015. Disponível em: <http://www.pewinternet. org/2015/04/09/teens-social-media-technology-2015/>. Acesso em: 19 dez. 2015.

LENHART, Amanda; SMITH, Aaron; ANDERSON, Monica; DUGGAN, Maeve; PERRIN, Andrew. Teens, Technology and Friendships. Pew Research Center [Site], 2015. Disponível em: <http://www.pewinternet.org/2015/08/06/teenstechnology-and-friendships/>. Acesso em: 19 dez. 2015.

MADDEN, Mary. LENHART, Amanda; CORTESI, Sandra; GASSER, Urs; DUGGAN, Maeve; SMITH, Aaron, BEATON, Meredith. Teens, Social Media and Privacy. Pew Research Center [Site], 2013. Disponível em: <http://pewinternet.org/ Reports/2013/Teens-Social-Media-And-Privacy.aspx>. Acesso em: 19 dez. 2013.

MADIANOU, Mirca; MILLER, Daniel. Polymedia: Towards a New Theory of Digital Media in Interpersonal Communication. International Journal of Cultural Studies, v. 16, n. 2, p. 169-187, 2013.

MARWICK, Alice E;; BOYD, Danah. I Tweet Honestly, I Tweet Passionately: Twitter Users, Context Collapse, and the Imagined Audience. New media \& society, v. 13, n. 1, p. 114-133, 2011.

MILLER, D. Facebook's So Uncool, But it's Morphing Into a Different Beast. The Conversation [Site], 2013. Disponível em: <http://theconversation.com/ facebooks-so-uncool-but-its-morphing-into-a-different-beast-21548>. Acesso em: 15 fev. 2016.

PELLANDA, Eduardo. Comunicação móvel: das potencialidades aos usos e aplicações. In: Intercom — Sociedade Brasileira de Estudos Interdisciplinares da Comunicação, XXXI Congresso Brasileiro de Ciências da Comunicação, Anais eletrônicos... Natal, RN - 2 a 6 de setembro de 2008. Disponível em: $<$ http://www. intercom.org.br/papers/nacionais/2008/resumos/R3-1727-1.pdf >. Acesso em: 10 jan. 2016. 
PRIMO, A.; SMANIOTTO, A. Blogs como espaços de conversação: interações conversacionais na comunidade de blogs insanus. E-Compos, 1(5), 2006. Disponível em: <http://www6.ufrgs.br/limc/ PDFs/conversacao.pdf> Acesso em: 21 dez. 2015.

PUTNAM, Robert D. Bowling Alone. New York: Simon \& Schuster Paperbacks, 2000.

RECUERO, Raquel. Comunicação Mediada pelo Computador e redes sociais na Internet. Porto Alegre: Sulina, 2012.

TATE, R. Facebook is 'Dead and Buried' to Teens, and That's Just Fine for Facebook. Wired [Site], 2013. . Disponível em: <http://www.wired.com/2013/12/facebookteens-2/>. Acesso em: 15 fev. 2016.

TURKLE, Sherry. Always on/Always on you: the tethered self. In: Handbook of Mobile Communications and Social Change, James Katz (ed). Cambridge, MA: MIT Press, 2006. Disponível em: <http://web.mit.edu/sturkle/www/Always-on\%20 Always-on-you The\%20Tethered\%20Self ST.pdf>. Acesso em: 10 jan. 2016.

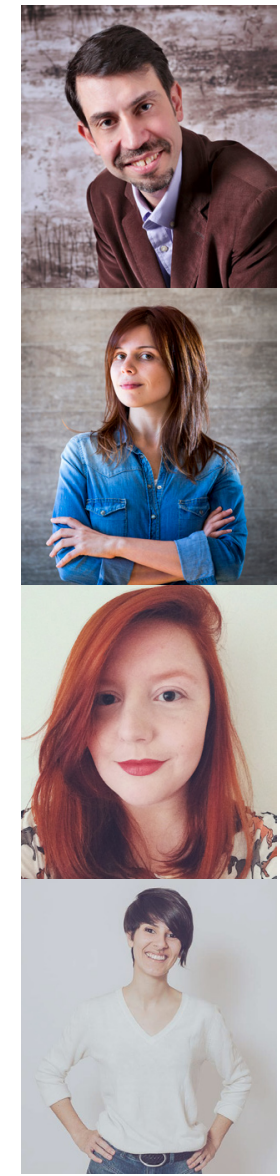

Recebido em: 15/7/2016

Aceito em: 18/7/2016

Endereço dos autores:

Alex Teixeira Primo <alex.primo@gmail.com>

Programa de Pós-Graduação em Comunicação e Informação da UFRGS

Faculdade de Biblioteconomia e Comunicação - Campus Saúde

Rua Ramiro Barcelos, 2705

90035-007 - Porto Alegre - RS - Brasil

Vanessa Valiati <vanessa.valiati@gmail.com>

Programa de Pós-Graduação em Comunicação e Informação da UFRGS Faculdade de Biblioteconomia e Comunicação - Campus Saúde Rua Ramiro Barcelos, 2705

90035-007 - Porto Alegre - RS - Brasil

\author{
Ludmila Lupinacci <ludmila.lupinacci@gmail.com> \\ Programa de Pós-Graduação em Comunicação e Informação da UFRGS \\ Faculdade de Biblioteconomia e Comunicação - Campus Saúde \\ Rua Ramiro Barcelos, 2705 \\ 90035-007 - Porto Alegre - RS - Brasil

